\title{
Magnitude of Anemia and Associated Factors Among Pregnant Women Visiting Public Health Institutions for Antenatal Care Services in Adama Town, Ethiopia
}

\author{
Ebrahim Mohammed, Ephrem Mannekulih, Mayrema Abdo
}

Department of Public Health, Adama Hospital Medical College, Adama, Ethiopia

Emailaddress:

ebrahim.m805@gmail.com (E. Mohammed),ephrem4emt@gmail.com (E. Mannekulih), meyremaabdo@gmail.com (M. Abdo)

\section{To cite this article:}

Ebrahim Mohammed, Ephrem Mannekulih, Mayrema Abdo. Magnitude of Anemia and Associated Factors Among Pregnant Women Visiting Public Health Institutions for Antenatal Care Services in Adama Town, Ethiopia. Central African Journal of Public Health.

Vol. 4, No. 5, 2018, pp. 149-158. doi: 10.11648/j.cajph.20180405.14

Received: August 13, 2018; Accepted: October 10, 2018; Published: October 25, 2018

\begin{abstract}
Anemia is a global public health problem. It affects more than 2 billion people worldwide, both in developing and developed countries. It affects people of all age groups. However, it is more prominent in pregnant women. It is estimated that approximately $41.8 \%$ of pregnant women worldwide affected by anemia. Institution based cross sectional study design was employed. A total of 424 pregnant women visiting public Health Institutions in Adama Town for Antenatal Care service was randomly selected. Data was collected using semi structured questioner and participants were interviewed at the exit of the Antenatal Care unit. Blood and stool sample was collected to determine the level of anemia and Middle Upper Arm Circumference measurement was measured to determine nutritional status of the mother. Data was entered into EPI-Info version 7 and imported into Statistical Package and Service Solution (SPSS) version 21 for data processing and analysis. Descriptive statistics were used to explore the characteristics of women and the magnitude of anemia. The association between the outcome variable (Anemia) and explanatory variable was analyzed using binary logistic regression. The effect of explanatory variable on Anemia was estimated using adjusted odds ratio (AOR) and $95 \%$ confidence interval was used for tests of significance. A total of 424 respondents participated in the study. The magnitude of Anemia was found to be $28.1 \%$ ( $\mathrm{P}=28.1$; 95\% CI: 23.6, 32.1). The highest level of anemia 79 (37.3\%) and $14(31.1 \%)$ was observed among women of age $25-34$ years old and third trimester respectively. Birth interval of more than 2 years (AOR, $0.29 ; 95 \%$ CI: $0.13,0.63$ ), Nutritional status of MUAC $<23 \mathrm{~cm}$ (AOR, 8.91; 95\% CI: 3.95, 20.11), taking tea (AOR, 5.49; 95\% CI: 2.16, 13.96) and taking coca cola or chocolate (AOR, 6.81; 95\% CI: 2.01, 23.12) and taking stimulant within 30 minutes after taking meal (AOR, 3.64; 96\% CI: $1.47,8.99)$ found to be significantly associated with the odds of having anemia during pregnancy. Magnitude of anemia is high (28.1\%) among pregnant women in Adama Town. Respondents' birth interval, nutritional status, type of stimulant and time of stimulant taking were found to be significantly associated to anemia in pregnant women. Health works should work on counseling of benefits of lengthening birth interval and delaying of taking stimulants after taking their meals.
\end{abstract}

Keywords: Adama, Anemia, Ethiopia

\section{Introduction}

Anemia is defined as a condition in which there is less than the normal hemoglobin (Hgb) level (Hgb level less than $11 \mathrm{gm} / \mathrm{dl})$ in the body which decreases oxygen-carrying capacity of red blood cells to tissues [1, 2]. Based on hemoglobin level, anemia in pregnant women can be classified as sever (Hgb level less than 7.0gm/dl), Moderate (Hgblevel7$9.9 \mathrm{gm} / \mathrm{dl}$ ) and mild (Hgblevel10-10.9 gm/dl) [3]. Based on the trimester of pregnancy, anemia will be diagnosed as the $\mathrm{Hgb}$ level less than $<11 \mathrm{gm} / \mathrm{dl}$ in first trimester, Hgb level less than $10.5 \mathrm{gm} / \mathrm{dl}$ in second trimester and Hgb level less than $11 \mathrm{gm} / \mathrm{dl}$ in third trimester [2]. Another classification of anemia is based on hematological indices like mean corpuscular volume (MCV) less than 80fl, mean corpuscular hemoglobin concentration (MCHC) less than 30\%, mean corpuscular hemoglobin $(\mathrm{MCH})$ less than $30 \mu \mathrm{g}$ are considered to indicate iron deficiency anemia (IDA) [4]. 
Anemia is global public health problem. It affects more than 2 billion people of different age groups worldwide both in developing and developed countries $[5,6]$. However, it is more prominent in pregnant women (PW), young children and other reproductive age groups [7]. It causes a high morbidity and mortality among antenatal mothers [8]. It is estimated that about $41.8 \%$ of pregnant women worldwide affected by anemia and theprevalencein South Asian countries is among the highest in the world. India is among the countries with the highest prevalence of anemia that is $87 \%$ and the prevalence is lower in Africa (57.1\%). The prevalence is $55.1 \%$ in Kenya. InEthiopiastudies shows different figures with regard to the magnitude of Anemia among pregnant mothers [9-11].

Some of the causes of anemia in pregnancy include iron deficiency, folate deficiency, vitaminB ${ }_{12}$ deficiency, hemolytic diseases, bone marrow suppression, chronic blood loss and underlying malignancies [12]. About $30-50 \%$ of woman becomes anemic during pregnancy, with iron deficiency being the most common form of anemia in more than $90 \%$ of cases. Iron requirements increase rapidly in the second and third trimester due to fetal growth; however iron absorption in the gut is not sufficient to meet this increased demand. Thus iron balance depends on maternal iron stores during this period [13]. Iron deficiency is the most common form of malnutrition in the world, affecting more than 2 billion people globally. Iron deficiency anemia (inadequate amount of red blood cells caused by lack of iron) is highly prevalent in less-developed countries but also remains a problem in developed countries where other forms of malnutrition have already been virtually eliminated [14]. Iron deficiency generally develops slowly and is not clinically apparent until anemia is severe even though functional consequences already exist. Where iron deficiency anemia is prevalent, effective control programs may yield benefits to Pregnant women and their infants; result in decreased low birth weight and prenatal mortality, decreased maternal mortality and obstetrical complications [14].

Anemia in pregnancy remains one of the most intractable public health problems in developing countries. Globally, anemia contributes to $20 \%$ of all maternal deaths. According to World Health Organization; the highest prevalence of anemia is reported in Africa and Southeast Asia. India is the country with the highest prevalence of anemia in pregnancy (49.7\%), against the globalprevalence of $41.8 \%$ [15]. Study conducted in Malaysia shows $33 \%$ of pregnant women were anemic with $\mathrm{Hgb}$ less than $11 \mathrm{gm} / \mathrm{dl}$ [16]. A recent study conduct in Pumwani Maternity Hospital in Kenya revealed $57 \%$ of pregnant women were anemic [17]. Studies conducted in different parts of Ethiopia shows different magnitude of anemia among pregnant women. About 21.6\% in Azazo, 61.6\% in Boditi, 27.7\% in Hawasa, 27.9\% in Bisidimo, and in Nekemte it was $29 \%$ and $52 \%$ in 2015 [1822]. From this we can see that there are disparities of magnitude of anemia among pregnant women different parts of the world and as well in Ethiopia.

Conceptual Framework

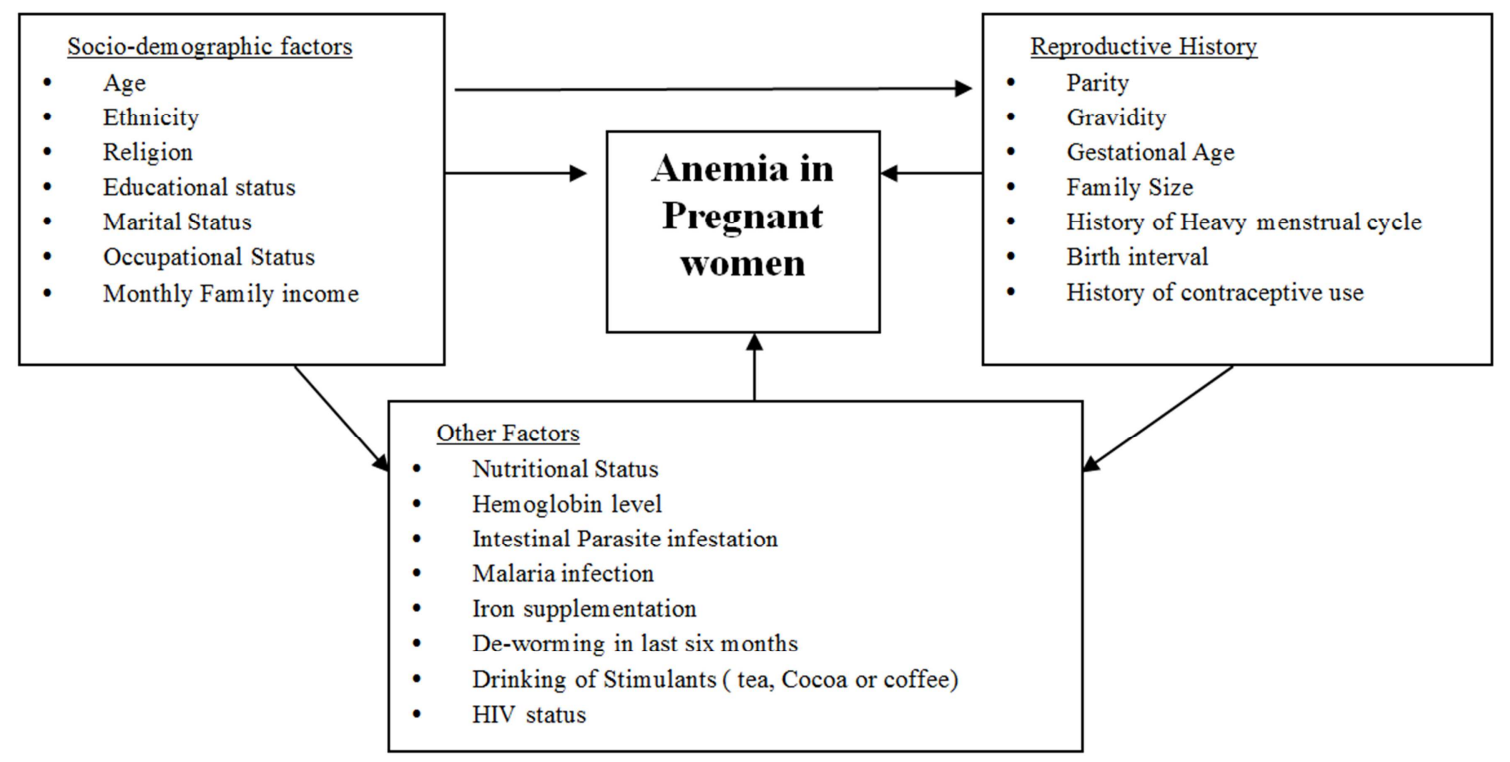

Figure 1. Conceptual framework developed based on review of literatures to assess factors associated with anemia among pregnant women in Adama town, Ethiopia, 2017.

\section{Methodsand Materials}

\subsection{Study Setting}

The study conducted in Adama Town, Oromia Regional State among women visiting Public Health Institutions for ANC services. Adama Town is located at about $100 \mathrm{Km}$
South-East of Addis Ababa, capital city of Ethiopia in the great rift valley of East Africa. It is located at $8^{0} 32$ to $8.54^{0}$ north latitude and $39^{\circ} 16^{\prime}$ to $39.27^{\circ}$ east longitudes at an elevation of 1,712 meters above sea level. Adama Town is one of the big cities of Ethiopia with an area of 13000 square $\mathrm{m}^{2}$ and has a total population of 337,556 . Adama Hospital Medical College hospital is found in Adama town and 
provides preventive and curative service for more than five million peoples. There are 1 governmental hospital, 7 governmental and 1 NGO's Health centers and two special clinics that provide ANC service

\subsection{Study Design and Period}

Health Facilities based cross sectional study design wasemployed among new ANC users visiting public health facilities in Adama town from May1-30, 2017.

\subsection{Population}

\subsubsection{Source population}

All pregnant womenwho leave inAdama Town.

\subsubsection{Study Population}

All pregnant women who visited public health institutions in AdamaTownfor ANC services during the study period from May 1-30, 2017.

\subsubsection{Study Unit}

A pregnant woman selected in public health institutions at exit from ANC services.

\section{Exclusion criteria}

Due to taking iron salphate for more than three months, pregnant women who attended ANC services for the three or more times in one of health institutions were excluded from the study.

\subsection{Sample Size Determination and SamplingProcedure}

\subsubsection{Sample Size Determination}

The sample size was determinedusing a formula used to estimation of a single population proportion. The proportion of Anemia (P) taken from similar institution based cross sectional study conducted in Nekemte town, Oromia regional state, Ethiopia, whichwas $52 \%$ among pregnant women. The sample size was determined with consideration of $95 \%$ confidence level, 5\% precision and 52\% Magnitude of Anemia among pregnant women. And $10 \%$ of the sample size was added to compensate for non-response. Accordingly, the sample size to estimate the magnitude of Anemia and the effect size of factors on Anemia among pregnant womenwas calculated as follow;

$$
\mathrm{n}=\frac{\left(\mathrm{Z}_{\frac{\alpha}{2}}\right)^{2} \mathrm{P}(1-\mathrm{P})}{\mathrm{d}^{2}}
$$

Where:

$\mathrm{n}=$ required sample size to determine magnitude and factors associated with Anemia among pregnant women,

$\mathrm{p}=$ proportion of anemia among pregnant women $52 \%$,

$\mathrm{d}=$ estimated margin of error for the study, $5 \%$ and

$Z_{\alpha / 2}=$ the corresponding value of confidence coefficient at alpha level of 0.05 that is 1.96

$$
\mathrm{n}=\frac{1.96^{2} \times(0.52)(0.48)}{(0.05)^{2}} \approx 384
$$

$10 \%(38)$ non response rate was added to the sample. Then the total samples size was 422 .

\subsubsection{Sampling Procedure}

A total of 422 pregnant women visiting Public Health Institutions in Adamatownwere selected from the total of pregnant women visiting Adama hospital medical college hospital ANC clinic. The first woman was selected randomly then every third pregnant women was selected at exit of ANC service. This sampling procedure wascarried on until the required sample size was achieved.

$\mathrm{N}=$ total sample size required $\mathrm{X}$ ANC service performance of health facility.

Total ANC service by health facilities.

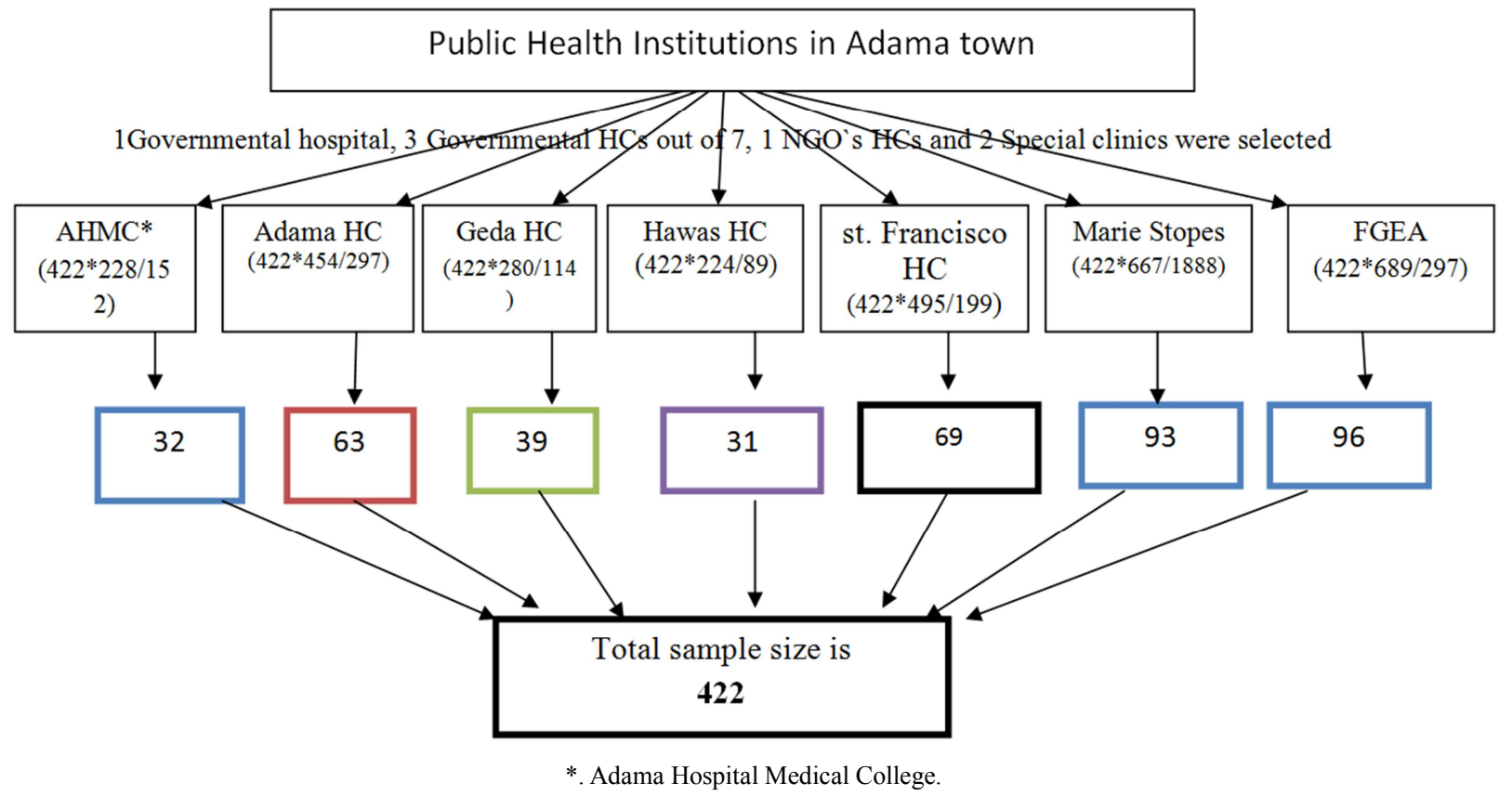

Figure 1. Sample allocation for selected health institution in adama town, Oromiya regional state, Ethiopia. 


\subsection{Study Variables}

\subsubsection{Dependent Variable}

Magnitude of Anemia

\subsubsection{Independent Variables}

Age, Ethnicity, Religion, Residence, Educational status, Marital Status, Occupational Status, Monthly Family income, Parity, Gravidity, Gestational Age, Family Size, History of Heavy menstrual cycle, Birth interval, History of contraceptive use, Nutritional Status, Hemoglobin level, Intestinal Parasite infestation, Malaria infection, Iron supplementation, De-worming in last six months, Drinking of stimulants(tea, Cocoa or coffee, etc).

\subsection{Data Collection Procedures}

For socio-demographic, reproductive history and other variables, Interviewer administered questionnaires was used to collect data from clients. Data was collected by trained female nurses. Data collectors are not employed in any institution. The nurses used a questionnaire and interview techniques to collect data from pregnant women in the selected health institutions. Clients were interviewed at exit of ANC service use. Questionnaires were adopted from similar studies conducted in Ethiopia and modified based on the objectives of the study [20,23]. Mixed type of questions (structured and semi-structured) was used to collect the data. The questionnaires were translated into two commonly locally spoken languages, Afan Oromo and Amharic in the study area.

Samples for laboratory investigation were collected using standards of sample collection methods. About 5 grams of stool was collected in wide mouth stool cup and was analyzed using microscope with $10 \mathrm{x}$ and 40x magnifying power on the spot(within 5-10 minute) in the health institution laboratory to investigate for parasitic infestation. For hemoglobin level determination, about $5 \mathrm{ml}$ of blood sample was collected using EDTA continuing tube and $\mathrm{Hgb}$ level was measured using CELL DYN 1800 by senior laboratory professionals. Standard (UNICEF made) MUAC tape measurement was used to analyze nutritional status of pregnant women.

\subsection{Data Quality Assurance}

Data was collected by trained female nurses. Data collection training was given for both data collectors and supervisors for 2 days including pre-test finding discussion and correction of data collection tools. Pretest of data collection was done in the Adama Health center and Geda health center in Adams town 1 week before data collection date. About 5\% (42) of the sample size was used for pretest. Then the data from pre-test was analyzed and questionnaires were re-adjusted based on the response from the pre-test. The data collection was started after one week of pre-test data collection. The data was checked for completeness and accuracy and corrected on the spot by supervisors. The investigators and supervisors weremeeting and discussed daily at the end of working hours of the data collection. Those data found missing in addressing important variables like the outcome and other important variables wasdiscarded and no longer was used as a predictor variable. The data was stored in a secured place for confidentiality and in time of need for a backup of the data.

\subsection{Data Processing and Analysis}

Data was coded and doubleentered into computer using EpiInfo Version 7 and was exported to SPSS version 21 statistical software for analysis. Descriptive analysis was used to reveal the magnitude of Anemia and explore the characteristics of women participated in the study. Before analysis the fulfillments of assumption for logistic regression was checked. Bivariatebinary logistic regression analysis will be applied to assess the crude relationship between independent variables and outcome variable (Anemia). At this level the candidate variables for multivariate analysis was selected at P-value < 0.25 significance level. Multivariate binary logistic regression was applied to estimate the adjusted effects of independent variables on outcome variable (Anemia). Odds ratio (OR) was used estimate the magnitude of association between independent variables and outcome variable (Anemia). And $95 \%$ CI was used to assess the statistical significance of association between independent variables and Anemia. The regression model was developed using backward stepwise strategy. The final fitted model was assessed for multicolliniarity using Variance Inflation Factor (VIF) and goodness of fit using Hosmer and Lemishow test. The model ability to correctly classify those subjects who experience outcome of interest and those who do not will be assessed using Receiver Operating Characteristics (ROC) curve. The parsimonious model that best explain data with minimum of free parameters was selected using Akaike Information Criteria (AIC).

\subsection{Ethical Considerations}

The ethical approval and clearance was obtained from AHMCInstitutional Review Board (IRB). Official letter of cooperation from AHMCwasreceived and respective officials of selected public health institutions for the study were communicated before the start of the study. All the study participants was informed about the purpose of the study and verbal consent of all study subjects will be obtained before data collection. Participants were informed that they have full right to discontinue or refuse to participate in the study or to be interviewed. To ensure confidentiality, the name of the interviewee will be not written on the questionnaire. The interview was made in a place where it is conducive to the study participants in the health institution compound. Each respondent was assured that the information provided by them will be kept confidential and used only for the purpose of research. Moreover, the study participants were informed there is no risk or harm that will be anticipated from participation in the study. 


\section{Result}

\subsection{Socio-Demographic Characteristics}

A total of 424 women of reproductive age (15-49 years) were participated in this study with $100 \%$ response rate. The majority $212(50.0 \%)$ of the participant was in the age range of $25-34$ years. Concerning the religion and ethnicity of participants, the majority $243(57.3 \%)$ of them were Orthodox and majority of participants 204 (48.1\%) of them were Oromo by their ethnicity. When we look at participants` educational status, the majority $169(39.9 \%)$ had attended primary (grade 1-8) education and $147(34.7 \%)$ had attended secondary education. Out of the total participants, the majority $393(92.7 \%)$ were married and 289 $(68.2 \%)$ of participants were housewives at the time of study. The majority $385(90.8 \%)$ live in urban. Regarding participant's monthly income, the majority 193(45.5\%) earns more than 2500 Birr per month (table 1).

Table 1. Socio-demographic characteristics of pregnant women in Adama town, Adama, Oromia regional state, Ethiopia 2017.

\begin{tabular}{|c|c|c|}
\hline Variables & Frequency (Number) & $\%$ \\
\hline \multicolumn{3}{|l|}{ Age Category } \\
\hline $15-24$ years & 193 & 45.5 \\
\hline $25-34$ years & 212 & 50.0 \\
\hline$>=35$ years & 19 & 4.5 \\
\hline \multicolumn{3}{|l|}{ Religious Category } \\
\hline Orthodox & 243 & 57.3 \\
\hline Muslim & 148 & 34.9 \\
\hline Protestant \& Catholics & 33 & 7.8 \\
\hline \multicolumn{3}{|l|}{ Ethnic Category } \\
\hline Oromo & 204 & 48.1 \\
\hline Amhara & 96 & 22.6 \\
\hline Gurage & 94 & 22.2 \\
\hline Others* & 30 & 7.1 \\
\hline \multicolumn{3}{|l|}{ Educational Level } \\
\hline Illiterate & 50 & 11.8 \\
\hline Primary(Grade 1-8) & 169 & 39.9 \\
\hline Secondary & 147 & 34.7 \\
\hline Certificate and Above & 58 & 13.7 \\
\hline \multicolumn{3}{|l|}{ Marital Status } \\
\hline Single & 31 & 7.3 \\
\hline Married & 393 & 92.7 \\
\hline \multicolumn{3}{|l|}{ Occupational Status } \\
\hline Merchant & 54 & 12.7 \\
\hline Gov. Employee & 31 & 7.3 \\
\hline House Wife & 289 & 68.2 \\
\hline Daily Laborer & 26 & 6.1 \\
\hline PLC Employee & 24 & 5.7 \\
\hline \multicolumn{3}{|l|}{ Monthly family income } \\
\hline$<=1500$ Eth. birr & 121 & 28.5 \\
\hline $1501-2500$ Eth. birr & 110 & 25.9 \\
\hline$>=2501$ Eth. birr & 193 & 45.5 \\
\hline \multicolumn{3}{|l|}{ Residence of respondent } \\
\hline Rural & 39 & 9.2 \\
\hline
\end{tabular}

*(Tigre, Silte, Wolayta, worji and Argoba).

\subsection{Obstetric and Other Related Factors}

Obstetric factors are some of the factors that may have effect on the magnitude of anemia among pregnant women. When we look at the obstetric characteristics of the study participant, more than half $258(60.8 \%)$ of them were multigravida and the majority $192(45.3 \%$ ) of participants` were nullipara(do not give birth before this pregnancy). Concerning the gestation age of the participant, the majority $322(75.9 \%)$ of them were in their second trimester and the mean age their gestation age was 20.31 weeks ( $\mathrm{SD} \pm 7.12)$. Regarding the history of abortion, only $90(21.2 \%)$ had abortion before the present pregnancy. Out of those who had abortion only $12(13.3 \%)$ of those had two and more than two abortions. Their family size and number of children they have been analyzed, the majority 200 (47.2\%) and $206(48.6 \%)$ of the respondent have 3 - 4 family size and $1-2$ children respectively. Most of 133 (53.8\%) the respondents gave their last birth within 2 years from their last birth and the majority $389(91.7 \%)$ of them do not have history of heavy menstrual bleeding. Regarding the history of contraceptive use, $333(78.5 \%)$ of the respondent use contraceptive and 196(58.9\%) of them used inject able contraceptives before this pregnancy.

Table 2. Reproductive and other related factors among pregnant women in Adama town, Oromia regional state, Ethiopia, 2017.

\begin{tabular}{|c|c|c|}
\hline Variables & $\begin{array}{l}\text { Frequency } \\
\text { (Number) }\end{array}$ & Percentage \\
\hline \multicolumn{3}{|l|}{ Gravidity } \\
\hline Primigravida & 166 & 39.2 \\
\hline Multi gravida & 258 & 60.8 \\
\hline \multicolumn{3}{|l|}{ Parity } \\
\hline Nulli Para & 192 & 45.3 \\
\hline Primi Para & 117 & 27.6 \\
\hline Multi Para & 115 & 27.1 \\
\hline \multicolumn{3}{|l|}{ Gestational Age } \\
\hline First trimester & 57 & 13.4 \\
\hline Second trimester & 322 & 75.9 \\
\hline Third Trimester & 45 & 10.6 \\
\hline \multicolumn{3}{|l|}{ History of abortion } \\
\hline No & 334 & 78.8 \\
\hline Yes & 90 & 21.2 \\
\hline \multicolumn{3}{|c|}{ Frequency of Abortion(N=90) } \\
\hline 1 time & 78 & 86.7 \\
\hline$\Rightarrow 2$ times & 12 & 13.3 \\
\hline \multicolumn{3}{|c|}{ Family size category } \\
\hline$<=2$ & 182 & 42.9 \\
\hline $3-4$ & 200 & 47.2 \\
\hline$>4$ & 42 & 9.9 \\
\hline \multicolumn{3}{|c|}{ Number of children category } \\
\hline None & 177 & 41.7 \\
\hline $1-2$ children & 206 & 48.6 \\
\hline$>2$ children & 41 & 9.7 \\
\hline \multicolumn{3}{|c|}{ Birth interval $(\mathrm{N}=247)$} \\
\hline$>2$ years & 133 & 53.8 \\
\hline$<=2$ years & 114 & 46.2 \\
\hline \multicolumn{3}{|c|}{ History of heavy menstrual bleeding } \\
\hline No & 389 & 91.7 \\
\hline Yes & 35 & 8.3 \\
\hline \multicolumn{3}{|c|}{ History of contraceptive use } \\
\hline No & 91 & 21.5 \\
\hline Yes & 333 & 78.5 \\
\hline \multicolumn{3}{|c|}{ Type of contraceptive used(N=333) } \\
\hline Oral pills & 78 & 23.4 \\
\hline Inject able & 196 & 58.9 \\
\hline Implants & 45 & 13.5 \\
\hline IUCD & 13 & 3.9 \\
\hline Others* & 1 & .3 \\
\hline
\end{tabular}

*natural method 
Regarding the suffering from chronic disease, almost 417(98.3\%) of participants are free from chronic diseases. But out of those who are suffering from chronic diseases the majority of pregnant women $4(57.1 \%)$ are suffering from diabetic mellitus. Out the total participants, about $157(37.0 \%)$ of them do not able to give stool at the time of study for stool examination. But the majority $267(63.0 \%)$ give their stool for parasitic infestation analysis. Out of those who give stool for parasitic infestation analysis, only $19(7.1 \%)$ of them were positive for intestinal parasite and the majority $11(57.9 \%)$ were positive for hook worm infestation. Regarding malarial infection, the majority $411(96.9 \%)$ of participants were no infected with malaria in the last one month before the study dates. Outof those infected with malaria, the majority $7(53.85 \%)$ were infected with falciparum. Concerning de-worming and supplementation with iron with folic acid, the majority $384(90.6 \%)$ and $340(80.2 \%)$ were not de-wormed and not supplemented respectively. Regarding use of ITN Only about 87 (20.5\%) of the study participants uses ITN at night.

When We look foruse of stimulants like coffee, tea, coca cola, chocolate, alcohol etc, among pregnant women the majority $345(81.4 \%)$ uses stimulants, and $122(35.6 \%)$ and $218(63.2 \%)$ ofthe study participant drink coffeeand take/drink stimulants within 30 minutes after taking their meal. Out of the total study participants, about $116(27.4 \%)$ of were malnourished wit MUAC less than $23 \mathrm{~cm}$. Concerning HIV status, the majority $405(95.5 \%)$ of the respondents were negative for HIV test. For detail description look at table 3 below.

Table 3. Other factors related to anemia during pregnancy among women of pregnant women in Adama town, Oromia regional state, 2017.

\begin{tabular}{|c|c|c|}
\hline Variables & Frequency(Number) & Percentage \\
\hline \multicolumn{3}{|l|}{ History of chronic disease } \\
\hline No & 417 & 98.3 \\
\hline Yes & 7 & 1.7 \\
\hline \multicolumn{3}{|l|}{ Type of chronic disease } \\
\hline TB & 2 & 28.6 \\
\hline $\mathrm{DM}$ & 4 & 57.1 \\
\hline Others & 1 & 14.3 \\
\hline No & 157 & 37.0 \\
\hline Yes & 267 & 63.0 \\
\hline \multicolumn{3}{|c|}{ Stool Exam Resultfor ova of intestinal parasite } \\
\hline Negative & 248 & 58.5 \\
\hline positive & 19 & 4.5 \\
\hline \multicolumn{3}{|l|}{ History of Malarial infection } \\
\hline No & 411 & 96.9 \\
\hline \multicolumn{3}{|l|}{ Type of Malaria species $(\mathrm{N}=13)$} \\
\hline P. Falciparum & 7 & 53.85 \\
\hline P. Vivax & 6 & 46.15 \\
\hline \multicolumn{3}{|l|}{ ITN use } \\
\hline No & 337 & 79.5 \\
\hline Yes & 87 & 20.5 \\
\hline \multicolumn{3}{|l|}{ De-warming } \\
\hline No & 384 & 90.6 \\
\hline Yes & 40 & 9.4 \\
\hline \multicolumn{3}{|l|}{ Iron and Folic acid supplementation } \\
\hline No & 340 & 80.2 \\
\hline Yes & 84 & 19.8 \\
\hline \multicolumn{3}{|c|}{ Frequency of taking Folic acidand Iron } \\
\hline One month & 28 & 33.3 \\
\hline Two months & 25 & 29.8 \\
\hline Three months & 28 & 33.3 \\
\hline No & 79 & 18.6 \\
\hline Yes & 345 & 81.4 \\
\hline \multicolumn{3}{|l|}{ Type of stimulantstaken } \\
\hline Coffee & 122 & 35.6 \\
\hline Tea & 88 & 25.7 \\
\hline Coca-Cola/Chocolate & 40 & 11.7 \\
\hline Coffee/Tea & 93 & 27.1 \\
\hline \multicolumn{3}{|l|}{ Time of stimulant taking } \\
\hline 30 minutes after taking meal & 97 & 28.1 \\
\hline 5-30 minutes after taking meals & 218 & 63.2 \\
\hline 30 before taking meals & 30 & 8.7 \\
\hline \multicolumn{3}{|l|}{ MUAC } \\
\hline $23 \mathrm{~cm}$ and above & 308 & 72.6 \\
\hline
\end{tabular}




\begin{tabular}{lll}
\hline Variables & Frequency(Number) & Percentage \\
\hline Less than $23 \mathrm{~cm}$ & 116 & 27.4 \\
HIV test result & & \\
Positive & 8 & 1.9 \\
Negative & 405 & 95.5 \\
Unknown & 11 & 2.6 \\
\hline
\end{tabular}

\subsection{Magnitude of Anemia}

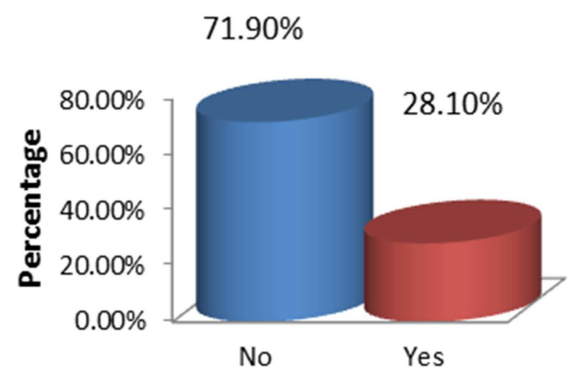

Figure 2. Magnitude of Anemia among pregnant women in Adama town, Ethiopia, 2017.

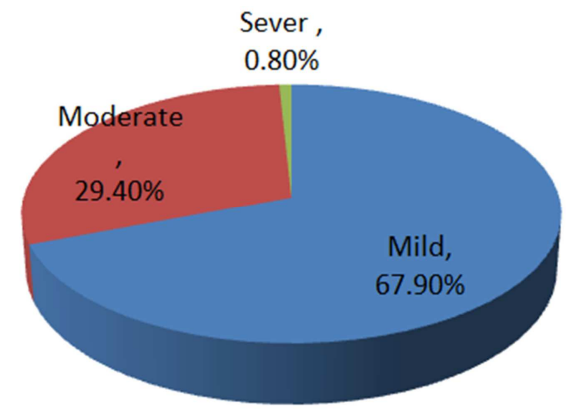

Figure 4. Severity of Anemia among pregnant women in Adamatown Ethiopia, 2017.

Before level of magnitude of anemia is analyzed, adjustment of hemoglobin to Altitude (hight) was made by subtracting 0.7 from measured $\mathrm{Hgb}$ level. After this adjustment, the result of this study shows that the magnitude of Anemia among pregnant women was 119(28.1\%) with $(\mathrm{P}=28.1$; 95\%CI: 23.6, 32.1) with the mean hemoglobin of $11.62 \mathrm{~g} / \mathrm{dl}(\mathrm{SD} \pm 1.28)$ and range $8.6 \mathrm{~g} / \mathrm{dl}$ (7-15.6) after adjustment of $\mathrm{Hgb}$ level to altitude. The highest level of anemia $79(37.3 \%)$ and $14(31.1 \%)$ was observed among women of age 25 - 34 years old and third trimester respectively. Regarding severity of anemia, the majority $83(69.7 \%), 35(29.4 \%)$ and $1(0.8 \%)$ of respondents were suffering from mild, moderate and severe anemia respectively. Severe anemia is $1(100 \%)$ more prevalent in second trimister of pregnancy and more $37(32.2 \%)$ prevalent in multipara women.

\subsection{Determinants of Anemia Among Pregnant Women}

After adjusting measured hemoglobin concentration to altitude, the variable related to or determined the prevalence of anemia in pregnant women, was analyzed using binary logistic regressions. Variables that were found significant at p. Value $<0.25$ during simple logistic regression analysis were taken to multiple logistic regression analysis. Variables like birth interval, nutritional status, type and time of taking stimulants were found to to be significantly associated with the odds having anemia.

Birth intervalfound significantly associated with anemia among pregnant women, women who have delayed their birth interval for more than two years had 71\%(AOR, 0.29; 95\% $\%$ : $0.13,0.63)$ lesser odds to be anemic compared women who space their birth for less than two years. Nutritional status was significantly association with anemia during pregnancy in the study area, being pregnant women with MUAC less than $23 \mathrm{~cm}$ were associated with 8.91(AOR, 8.91; 95\% CI:3.95, 20.11) times higher odds of developing anemia compared to pregnant women with MUAC greater or equal $23 \mathrm{~cm}$. Another factors, taking or drinking stimulants like tea, coca cola or chocolate and time of dinking or taking shows significant association with anemia during pregnancy, the odds of having anemia among pregnant women who take tea, coca cola or chocolate with meal were 5.49 (AOR, 5.49; 95\% CI: 2.16, 13.96) and 6.81(AOR, 6.81; 95\% CI: 2.01, 23.12) times higher compared to those who take or drink coffee. Not only the types of stimulants were significantly associated with anemia during pregnancy, time of taking or drinking was significantly associated with anemia. Pregnant women who drink or take stimulant within 30 minutes after taking their meal were 3.64 (AOR, 3.64; 96\% CI: 1.47, 8.99) time higher odds to be anemic compared to those who take stimulants after 30 minutes of taking their meals (table 3 ).

Table 4. Determinants of anemia among pregnant in Adamatwon, Oromia regional state, Ethiopia, 2017.

\begin{tabular}{|c|c|c|c|c|c|}
\hline \multirow{2}{*}{ Variables } & \multicolumn{4}{|l|}{ Anemia } & \multirow{2}{*}{$\mathrm{P}<0.05$} \\
\hline & No & Yes & $\operatorname{COR}(95 \% \mathrm{CI})$ & $\operatorname{AOR}(95 \% \mathrm{CI})$ & \\
\hline \multicolumn{6}{|l|}{ Birth Interval $(\mathrm{N}=247)$} \\
\hline$<=2$ years & $69(60.5 \%)$ & $45(39.5 \%)$ & 1.00 & & \\
\hline$>2$ years & $104(78.2 \%)$ & $29(21.8 \%)$ & $0.43(0.25,0.75)$ & $0.29(0.13,0.63)$ & 0.002 \\
\hline \multicolumn{6}{|l|}{ Nutritional status } \\
\hline Not malnourished(MUAC $\geq 23 \mathrm{~cm}$ ) & $262(85.1 \%)$ & $46(14.9 \%)$ & 1.00 & & \\
\hline Malnourished(MUAC $<23 \mathrm{~cm})$ & $43(48.9 \%)$ & $45(51.1 \%)$ & $9.67(5.92,15.78)$ & $8.91(3.95,20.11)$ & 001 \\
\hline \multicolumn{6}{|l|}{ Time of taking stimulants } \\
\hline 30 minutes after taking meals & $79(81.4 \%)$ & $18(18.6 \%)$ & 1.00 & & \\
\hline
\end{tabular}




\begin{tabular}{|c|c|c|c|c|c|}
\hline \multirow{2}{*}{ Variables } & \multicolumn{4}{|l|}{ Anemia } & \multirow{2}{*}{$\mathbf{P}<0.05$} \\
\hline & No & Yes & COR $(95 \% \mathrm{CI})$ & AOR (95\% CI) & \\
\hline Within 30 minutes after taking meals & $140(64.2 \%)$ & $78(35.8 \%)$ & $2.45(1.37,4.38)$ & $3.67(1.47,8.99)$ & 0.005 \\
\hline 30 minutes before taking meals & $21(70.0 \%)$ & $9(30.0 \%)$ & $1.88(0.74,4.79)$ & $4.08(0.98,17.10)$ & 0.054 \\
\hline \multicolumn{6}{|l|}{ Type of stimulants } \\
\hline Coffee & $99(81.1 \%)$ & $23(18.9 \%)$ & 1.00 & & \\
\hline Tea & $43(48.9 \%)$ & $45(51.1 \%)$ & $4.51(2.43,8.35)$ & $5.49(2.16,13.96)$ & 0.001 \\
\hline Coca-Cola/Chocolate & $25(62.5 \%)$ & $15(37.5 \%)$ & $2.58(1.18,5.66)$ & $6.81(2.01,23.12)$ & 0.002 \\
\hline Coffee/Tea & $75(76.3 \%)$ & $22(23.7 \%)$ & $1.33(0.69,2.58)$ & $1.99(0.68,5.77)$ & 0.208 \\
\hline
\end{tabular}

\section{Discussion}

The magnitude of anemia in this study area using a cut off level of $\mathrm{Hb}<11 \mathrm{~g} / \mathrm{dl}$ is $28.1 \%$. The magnitude of Anemia in pregnant women in the study area is lower compared to global prevalence (41.8\%), India(49.7\%), Malaysia(33\%), Kenya (57\%), Boditi (Ethiopia) (61.6\%), Nekemte 2014) (29.0\%), Nekemte (2015, Ethiopia) (52\%) and Addis Ababa (TikurAnbesaHospial, Ethiopia) (33\%) [15-17, 21-24]. But higher compared to the study conducted indifferent parts of Ethiopia; Azezo (21.6\%), in Hawasa town (27.7\%) and Bisidimotown (27.9\%) [18-20]. This difference could be due to difference in geographical location, culture and feeding behavior.

Concerning the severity of anemia among PW, this study reveals thatabout $69.7 \%, 29.4 \%$ and $0.8 \%$ of the study participants had mildanemia(Hgb 10.0-10.9g/d1), moderate anemia (Hgb 7.0 - $9.9 \mathrm{~g} / \mathrm{dl})$ and severe anemia $(\mathrm{Hgb}<7 \mathrm{gm} / \mathrm{d} 1)$ respectively. A similar condition with highest mild type, lower moderate type and lowest severe type PW anemia was observed in Pakistan in which majority of the cases had mild anemia $(75.0 \%)$, moderate anemia $(14.8 \%)$ and severe anemia $(0.7 \%)$. The result of this study is quite different from study conducted in India in which the majority $(50.9 \%)$ of the study participant were moderately anemic and severe anemia was high $(18.9 \%)[25,26]$. The similarity and difference in the results of the studies could geographic location (Altitude difference), feeding behavior and economic status.

Factor like birth interval, Nutritional status type and time of taking stimulants were significantly associated with anemia during pregnancy. This study shows negative association with birth interval, thatiswomen who delay giving birth were $71 \%$ less likely to be anemic during pregnancy. Theresult of this is congruent to study conducted inIndia (Kolar District) whichstates that as the birth interval increase, the probability of being anemic is decreased among pregnant women and Study conducted in Arba Minch(Ethiopia) shows that having birth interval less than two years is significantly associated anemia in a pregnant women [27, 28]. The similarity may be due to the fact that as birth interval is less than two years high bleeding during birthmay lead anemia.

This study reveals that nutritional status of pregnant women was strongly associated with anemia during pregnancy. Pregnant women of MUAC (SAM) less than $23 \mathrm{~cm}$ were 8.91 times more likely to be anemic compared to women not malnourished. The result of this study is comparable with the study conducted in Kenya, Sidama and Wolytasodo (Ethiopia) [29, 30]. The similarity could be due the fact that anemia can be caused due to malnutrition. This study assessed the association of type and time of taking stimulants with anemia. This study revealed that drinking tea and time of taking stimulants within 30 minutes after taking meals is significantly associated with anemia during pregnancy. The result of this study is opposite to the study conducted in Kenya [17], the reason could be that the investigator of study conducted in Kenya did not investigate types of stimulants and time of taking. It was investigated only taking of stimulants could be related to anemia during pregnancy.

\section{Conclusion}

Anemia in pregnant women is found to $28.1 \%$ in the study area. Still it is higher compared to study conducted in Azezo(21.6\%), Northern part of Ethiopia but lower than WolaytaSodo (39.94\%) and Boditti (61.6\%). Anemia is very prevalent at the age of $25-34$ years old. Factors like birth interval(Child Spacing), nutritional status, type and time of taking stimulants were significantly associated with anemia in pregnant women in the study area.

\section{Strengthand Limitation}

\subsection{Strength}

Primary data were collected by trained data collectors (female nurses) at post service (service exist) by interview data collection method. Blood and stool sample was collected. Two days training were given for the data collectors including pretest data collection. Pretest was done to check the validity and reliability. Structured questionnaires were used to collect data from clients.

\subsection{Limitation of the Study}

As this study was institution based study and conducted in urban areas among ANC service users, it might undermine generalization of the study result to the general population including rural community and none pregnant women. The study design is cross-sectional; therefore it may be difficult to establish a temporal relationship. About $37 \%$ of the study participants were not able to give stool sample at the time of data collection; this limits analysis of level parasitic infestation. 


\section{Recommendation}

It is recommend all women to space their birth for more than two years to prevent anemia that may be occurred due to repeated blood loss during delivery. And again, delaying of taking stimulants with in thirty minutes after taking their meal isrecommend.

All concerned bodies, health works should work on counseling about family planning service and benefits in relation to lengthening birth interval and prevention of anemia during pregnancy focusing on women of age 25-34 years, age of high risk for anemia.

Health workers should counsel individuals, family and as a whole community about pregnant women feeding and problems of being malnourished during pregnancy to prevent anemia.

Health works should give health education on the advantages and disadvantages of taking stimulants especially tea, coca cola or chocolate and delaying of the time of taking the stimulants after taking meal.

Researchers need to focus on investigation of the correlation of taking specific stimulants like tea, coffee, coca cola chocolateetc. of anemia during pregnancy.

\section{Acknowledgements}

The authors want to acknowledge data collectors, Head of health institutions (Adama Hospital Medical College, Adama HC, Geda HC, St. Francisco HC, Marie stopesAdama clinic and Family Guidance Association of Adama Clinic) from which the data was collected for their support and facilitation of data collection. Authorsgratitude heart felt goes to study participants who give their blood and time for investigation

\section{References}

[1] World Health Organization and U. N. University/UNICEF:, Iron Deficiency Anemia, Assessment, Prevention and Control: AGuide for Programme Managers. 2001: Geneva.

[2] Organisation, W. H., Haemoglobin concentrations for the diagnosis of anaemia and assessment of severity. Vitamin and Mineral Nutrition Information System., in Available fromURL:http://www.who.int/vmnis/indicators/haemoglobin.p df. 2011: Geneva.

[3] Balarajan Y, et al., Anemia in low-income and middle income countries. The Lancet, 2008. 378: p. 2123-2135.

[4] Abbassi-Ghanavati M, Greer LG, and Cunningham FG, Pregnancy and laboratory studies: A reference table for clinicians. for clinicians. Obstet Gynaecol Vol. 114. 2009. 1326-31.

[5] Mlean E, et al., World wide prevalence of anemia. WHO vitamins and mineral nutrition information system: 1993-2005: Public health Nutrition 2008. 12(4): p. 444-454.

[6] E. Mlean, et al., Worldwide prevalence of anaemia, WHO Vitaminand Mineral Nutrition Information System,. Public Health Nutrition, 2009. 12(4): p. 444-454.
[7] Ma AG, et al., Anemia prevalence among pregnant womenand birth weight in five areas in China. Medical principle and practice, 2009. 18: p. 368-372.

[8] Rasheed P, et al., Anemia in pregnancy: A study among attendees of primary health care centers. Ann Saudi Med. Ann SaudiMed 2008. 28: p. 449-452.

[9] De Benoist B, et al., Worldwide prevalence of anemia: 19932005: WHO database on anemia. 2008, WHO: Geneva.

[10] Ministry of health and R.o. Kenya., National Iron and Folic acid supplementation communication strategies,. 2013, Government of Kenya: Nirobi.

[11] Suryanarayana R, et al., Prevalence of anemia among pregnant women in rural population of Kolar district. Int J Med Sci Public Health, 2016. 5: p. 454458.

[12] Reveiz L, Gyte GMI, and C. LG, Treatments for irondeficiency anaemia in pregnancy. The Cochrane Database of Systematic reviews, 2007. 2.

[13] TA., J., Anaemia. In:. Obstetrics and Gynaecology An evidence-based text for MRCOG, ed. B. P. Luesley DM, editors. 2010, London: Hodder Arnold.

[14] Stoltzfus, R. J. and M. L. Dreyfuss, eds. Guidelines for the Use of Iron Supplements to Prevent and Treat Iron Deficiency Anemia. International Life Sciences Institute: 1126 Sixteenth Street, N. W. Washington, D. C. 20036-4810:ISBN 1-57881020-5.

[15] World Health Organization (2008), The Prevalence of Anaemia in Women: A Tabulation of Available Information 2008: Geneva.

[16] Kim Lam Soh, et al., Anemia among Antenatal Mother in Urban Malaysia Journal of Biosciences and Medicines, 2015. 3: p. 6-11.

[17] Okubatsion Tekeste Okube, et al., Prevalence and Factors Associated with Anaemia among Pregnant Women Attending Antenatal Clinic in the Second and Third Trimesters at Pumwani Maternity Hospital, Kenya Open Journal of Obstetrics and Gynecology, 2016. 6: p. 16-27.

[18] Mesret Alem, et al., Prevalence of Anemia and associated factors among pregnant women attending ANC in Azezo health center gonder town, North west Ethiopia. J Interdiscipl Histpathol, 2013. 1(3): p. 137-144, ISSN:2146-8362.

[19] Kefiyalew and et al, Anemia among pregnant women in Bisidimo, Southeast Ethiopia: prevalence, severity and associated risk factors. BMC research Notes,, 2014. 7: p. 771.

[20] Wondu $\mathrm{T}$ and $\mathrm{M}$ Bijlsma, The hidden hunger": Understanding the burden of Anaemia and its determinants among pregnantAnd non-pregnant women in Hawasa, Ethiopia. AJFAND, 2012. 12(7): p. 6913-6930, ISSN: 1684-5374.

[21] Dereje Lelissa, et al., Prevalence of Anemia Among Women Receiving Antenatal Care at Boditii Health Center, Southern Ethiopia. Clinical Medicine Research, 2015. 4(3): p. 79-86, doi:10.11648/j.cmr.20150403.14.

[22] Eyasu Ejeta, et al., Prevalence of Anaemia in Pregnant Womens and Associated Risk Factors in Nekemte Town, Western Ethiopia Food Science and Quality Management 2014. 31: p. 82-91, ISSN: 2224-6088 (Paper) ISSN 22250557 (Online). 
[23] Mihiretie H, et al., Magnitude of Anemia and Associated Factors among Pregnant Women Attending Antenatal Care in Nekemte Health Center, Nekemte, Ethiopia. J Med Microb Diagn, 2015. 4: p. 197. doi:10.4172/21610703.1000197.

[24] Jufar AH, Z. T., Prevalence of Anemia among Pregnant Women Attending Antenatal Care at Tikur Anbessa Specialized Hospital, Addis Ababa Ethiopia. J Hematol Thromb Dis 2: 125 doi: $10.4172 / 2329-8790.1000125$.

[25] Vijaynath 1, et al., Prevalence of anemia in pregnancy. Indian Journal of Applied Basic Medical Sciences2010. 12: p. 23-35.

[26] Vijaynath and et al., Prevalence of anemia in pregnancy. Indian Journal of Applied Basic Medical Sciences 2010. 12: p. 23-25.

[27] Suryanarayana R, et al., Prevalence of anemia among pregnant women in rural population of Kolar district. Int J Med Sci Public Health 2016;5:454-458, 2016. 5: p. 454-458.
[28] Alemayehu Bekele, Marelign Tilahun, and A. Mekuria, Prevalence of Anemia and Its Associated Factors among Pregnant Women Attending Antenatal Care in Health Institutions of Arba Minch Town, GamoGofa Zone, Ethiopia: A Cross-Sectional Study. Hindawi Publishing Corporation. Volume 2016, Article ID 1073192, 9 pages.

[29] Samson Gebremedhin, Fikre Enqusilassie, and M. Umeta, Prevalence and Correlates of Materna Anemia in Rural Sidama, Southern Ethiopia. African Journal of Reproductive Health March 2014. 18(1): p. 44.

[30] Lealem G and et al, Anemia and associated factors among pregnant women attending antenatal care clinic in Wolayita Sodo town, Southern Ethiopia EJHS, 2015. 25(2): p. 155-162. 